\title{
GAS CHROMATOGRAPHY-MASS SPECTROMETRY ANALYSIS, IN VITRO ACTIVITIES, AND IN SILICO MOLECULAR DOCKING OF MAJOR COMPONENTS OF MICHELIA ALBA DC ESSENTIAL OIL AND SCENTED EXTRACTS
}

\author{
THONGCHAI KHAMMEE ${ }^{1 *}$, AMORNMART JARATRUNGTAWEE ${ }^{2}$, MAYOSO KUNO ${ }^{3}$ \\ ${ }^{1}$ Department of Chemistry, Faculty of Science and Technology, Phranakhon Rajabhat University, Bangkhen, Bangkok, Thailand. \\ ${ }^{2}$ BrukerBiospin AG, Ratchathewi, Bangkok, Thailand. ${ }^{3}$ Department of Chemistry, Faculty of Science, Srinakharinwirot University, \\ Sukhumvit 23, Bangkok, Thailand. Email: thongchai.k@pnru.ac.th
}

Received: 10 August 2018, Revised and Accepted: 26 September 2018

ABSTRACT

Objective: The essential oil and scented extracts of Michelia alba DC. were analyzed by gas chromatography-mass spectrometry (GC-MS) and investigated for antidiabetic activities in vitro and in silico.

Methods: The identification of steam distilled essential oil and scented extracts of $M$. alba was performed by GC-MS on the Agilent 7890A chromatograph couple with GC-7000 Mass Triple Quadrupole. The extractions have been evaluated the antidiabetic activities by alpha-amylase ( $\alpha$-amylase) assay using starch as substrates. In addition, computational molecular docking analysis of significant components was studied to understanding how selected compounds interacted with $\alpha$-amylase using AutoDock 4.2.

Results: The yields of M. alba of steam distilled essential oil and solvent extractions including hexane, diethyl ether, and dichloromethane were $0.16 \%$, $0.02 \%, 0.47 \%$, and $0.92 \%$, respectively. GC-MS analysis of essential oil revealed that the main component was monoterpenoids $\beta$-linalool (65.03\%). Meanwhile, 2-methylbutanoic acid was a primary in hexane extract (36.54\%) and dichloromethane extract (33.07\%). In the case of ether extract, the primary compound was $\beta$-linalool (37.32\%) same as in essential oil. The antidiabetic activities evaluation demonstrates that essential oil and scented extracts have shown promising $\alpha$-amylase inhibition activity. Essential oil from steam distillation revealed the best inhibition potential with a half maximal inhibitory concentration value of $0.67 \pm 4.7 \mathrm{mg} / \mathrm{ml}$ and their significant components demonstrated negative binding energies, indicating a high affinity to the $\alpha$-amylase-binding site using molecular docking simulation.

Conclusion: Data from this study suggest that essential oil and scented extracts of $M$. alba DC possess in vitro $\alpha$-amylase activities and can be used for therapy of diabetes.

Keywords: Solvent extraction, Essential oil, Antidiabetic activities, Gas chromatography-mass spectrometry.

(C) 2018 The Authors. Published by Innovare Academic Sciences Pvt Ltd. This is an open access article under the CC BY license (http://creativecommons. org/licenses/by/4. 0/) DOI: http://dx.doi.org/10.22159/ajpcr.2018.v11i12.29043

\section{INTRODUCTION}

Diabetes mellitus is a metabolic disorder regarding hyperglycemia is associated with an interrupt of carbohydrate, fat, and protein metabolism consequences of deficiency in insulin secretion, insulin action, or both [1]. A therapeutic approach to treating diabetes is to decrease postprandial hyperglycemia. The diabetic treatment can be achieved through the inhibition of carbohydrate-hydrolyzing enzymes such as $\alpha$-amylase. $\alpha$-amylase inhibitors are drug-design targets in the development of compounds for the treatment of diabetes, obesity, and hyperlipemia [2-4]. Although $\alpha$-amylase inhibitors have been shown to be effective in controlling blood sugar levels in people with diabetes, it can have annoying and adverse side effects, especially nausea, vomiting, flatulence, and diarrhea [5]. Due to the existing commercially available drugs have many limitations, the search for new promising antidiabetic is urgently needed. Accordingly, many efforts have been made to investigate for other useful and safe enzyme inhibitors from natural materials to control diabetes [6,7]. Historically, plants have been played a key role in traditional medicine for the treatment of diabetic although they are not clinically regulated due to lack of data to support the reported therapeutic. Many of the plant species with diabetic activity were native to tropical countries, due to the extraordinary biodiversity in these countries [8]. For instance, Thailand has tremendous biodiversity [9]. Thailand is consecrated with a rich source of medicinal and aromatic plants, many of plants which have not been well investigated for their chemical constituents and biological activities. There is considerable evidence that plant extracts, essential oils, and purified phytochemicals can be developed into drugs that can be used as preventive or treatment therapies for several diseases. Especially, essential oils from plants or herbs have found applications in folk medicine, food flavoring, and preservation, as well as in fragrance industries [10] and have been shown to possess possible health benefits with broad-spectrum bioactivity $[11,12]$.

Michelia alba DC (family Magnoliaceae) also known as the Jampee (Thailand) and White champaca (Indonesia) is a flowering plant of hybrid origin that is commonly cultivated in Southeast Asia and tropical regions of East Asia. M. alba is a medium-sized tree up to $20 \mathrm{~m}$ tall [13]. The white bell-shaped flowers most have a delightful aroma that is most intense during the early part of the day and bloom year-round. The sweet and robust fragrance made them an ideal ingredient for aromatherapy products. Furthermore, flowers of M. alba are used for heart maintenance and antipyretics in Thailand [14]. M. alba is also used in the prevention of bronchitis, prostatitis, and leucorrhea in India [15]. M. alba have been studied extensively in extraction methods and chemical constituents by gas chromatography (GC) or GC-mass spectrometry (GC-MS) analysis [16-18]. However, their clinical applications for the treatment of diabetes are still an absence.

The aim of this study is to identify their components and to evaluate the M. alba essential oil and scented extracts for its antidiabetic activity using $\alpha$-amylase assay to find out new active plants for therapy of diabetes. Furthermore, in silico molecular docking of significant constituents 
was studied. By molecular docking, the bound conformations and the binding affinity between chemical constituent and alpha-amylase as a target could be predicted.

\section{MATERIALS AND METHODS}

\section{Chemicals and materials}

Plants sample collection

The M. alba flowers were collected from Bang Kruai district Nonthaburi Province, Thailand $\left(13^{\circ} 48^{\prime} 13.0 » \mathrm{~N} 100^{\circ} 22^{\prime} 20.0 » \mathrm{E}\right)$, between 1:00 am and 3:00 am, in October 2017.

\section{Isolation of essential oil}

\section{Steam distillation}

The fresh floral material (200 g) was placed in a round bottom flask with $500 \mathrm{ml}$ of distilled water and then boiled for $3 \mathrm{~h}$. After this time, the recovered emulsion of oils and water was extracted with dichloromethane $(3 \times 15 \mathrm{ml})$ and then concentrated in a rotary evaporator Buchi ${ }^{\circledR}$ model R-114 under vacuum at $45^{\circ} \mathrm{C}$ for evaporating the solvent as much as possible. The pale yellow oil was obtained and has a boiled floral odor. The oil was transferred to an amber vial with a Pasteur pipette. Oil yield was calculated by the weight of the solventfree crude and dividing by the weight of the initial dry weight and multiplying by 100 . The obtained oil was stored in an amber glass bottle and stored at $4^{\circ} \mathrm{C}$ until further analyses.

\section{Solvent extraction}

The fresh $M$. alba petals (250 g) were extracted with each of the solvents $(250 \mathrm{ml})$, hexane, diethyl ether, and dichloromethane at room temperature using the maceration method for $24 \mathrm{~h}$ and then filtered through Whatman no. 1 filter paper. Anhydrous sodium sulfate was added to remove the traces of water. The crudes were extracted twice with the same fresh solvent and combined. Then, the combined extracts were evaporated in vacuo at low temperature $\left(40{ }^{\circ} \mathrm{C}\right)$ using a rotary evaporator and finally left the semi-solid residue of essential oil (concrete). The obtained concrete was stored in an amber glass bottle and stored at $4^{\circ} \mathrm{C}$ until further analyses.

\section{GC-MS analysis}

An Agilent GC-MS (Agilent 7890A GC-7000 Mass Triple Quad) was used for this analysis. Ethyl acetate was used to dilute oil samples, and $1 \mu \mathrm{l}$ of the extract was injected into a DB-Wax $(60 \mathrm{~m} \times 0.25 \mathrm{~mm}$ i.d. $\times 0.25$ $\mu \mathrm{m}$ film thickness) fused silica capillary column (J \& W Scientific, Folsom, CA). Temperatures for injector were set at $250^{\circ} \mathrm{C}$, and split mode was applied to the ratio of $20: 1$. The flow rate of helium gas (carrier gas) was set to $1.0 \mathrm{ml} / \mathrm{min}$. The following oven temperature program was used: Column temperature was isothermally maintained at $30^{\circ} \mathrm{C}$ for $5 \mathrm{~min}$, then programmed at a rate of $5^{\circ} \mathrm{C} / \mathrm{min}$ to $240^{\circ} \mathrm{C}$, and maintained isothermally at $240^{\circ} \mathrm{C}$ for $20 \mathrm{~min}$. The mass spectrometer was used in the electron ionization mode with the ion source temperature set at $250^{\circ} \mathrm{C}$ and the ionization energy set at $70 \mathrm{eV}$. The scan mode was used, and the scan range was $30-400 \mathrm{~m} / \mathrm{z}$. The data analysis was performed with MassHunter software. Identification of volatile compound was performed by comparing mass spectra with NIST mass spectral libraries (National Institute of Standards, 2011 version). The content of volatile compounds was calculated from the peak areas.

\section{$\alpha$-Amylase inhibitory activity}

The $\alpha$-amylase inhibitory activity of essential oil and extracts was carried out according to the 3,5-dinitrosalicylic acid (DNS) method as described by Unnikrishnan [19] with minor modification. Briefly, $50 \mu \mathrm{l}$ of essential oils and scented extracts with varying concentrations $(25-1000 \mu \mathrm{g} / \mathrm{ml})$ and $250 \mu \mathrm{l}$ of $0.02 \mathrm{M}$ sodium phosphate buffer saline ( $\mathrm{pH}$ 6.9) containing $\alpha$-amylase (TCI, Tokyo, Japan) solution $(1.5 \mathrm{mg} / \mathrm{ml})$ were preincubated for $10 \mathrm{~min}$ at $37^{\circ} \mathrm{C}$. $250 \mu \mathrm{l}$ of $1 \%$ starch solution in $0.02 \mathrm{M}$ sodium phosphate buffer saline ( $\mathrm{pH}$ 6.9) was added. The reaction was incubated further at $37^{\circ} \mathrm{C}$ for $30 \mathrm{~min}$. After incubation, $500 \mu \mathrm{l}$ DNS (TCI, Tokyo, Japan) color reagent was then added and boiled for $10 \mathrm{~min}$ and cooled at room temperature. The reaction mixture was then diluted by adding $1 \mathrm{ml}$ of DI water. The absorbance of the reaction mixture was read at $540 \mathrm{~nm}$ using Victor Nivo multimode microplate reader (PerkinElmer). Acarbose (TCI, Tokyo, Japan) at various concentrations (10-125 $\mu \mathrm{g} / \mathrm{ml})$ was used as a standard. Each experiment was done in triplicates. The results were considered as percentage inhibition, which was calculated using the following equation:

Inhibitoryactivity $(\%)=\frac{A_{\text {control }}-A_{\text {sample }}}{A_{\text {control }}} \times 10 C$

Where, $\mathrm{A}_{\text {sample }}$ is the absorbance value of the test substance, and $\mathrm{A}_{\text {control }}$ is the absorbance value of the control.

The percentage $\alpha$-amylase inhibition was plotted against the extract concentration, and the half maximal inhibitory concentration (IC50) values were obtained from the graph.

\section{Molecular docking simulation}

Crystal structure of human pancreatic $\alpha$-amylase in complex with nitrate and acarbose (3BAJ) was obtained from the Protein Data Bank [20]. The preparation of the target enzyme with the AutoDock tools involved in the addition of hydrogen atoms to the target enzyme, which is a necessary step for the computation of partial atomic charges. Gasteiger charges were considered for each atom present in the target in AutoDock 4.2. Three-dimensional affinity grids of size $100 \times 100$ $\times 100 \AA$ with $0.375 \AA$ spacing on the geometric center of the target and were considered for each of the following atom types: A, C, HD, $\mathrm{N}, \mathrm{NA}, \mathrm{OA}$, and SA, representing all probable atom types in the target enzyme [21]. The ligands were built using ChemSketch (ver.11.0, ACD/ Labs, Ontario, Canada) and optimized using Gaussian 03 molecular simulation software (Gaussian, Inc., CT, USA) [22]. The optimized ligand molecules were docked into the $\alpha$-amylase enzyme using AutoDock (ver. 4.2, Scripps Research Institute, CA, USA).

The energy evaluation was attained by pre-calculating the atomic resemblance potentials for each atom in the selected compounds. In the AutoGrid process, the target was enclosed on a three-dimensional grid point, and the energy interface of each atom in the ligands was encountered. The following docking factors were chosen for the Lamarckian genetic algorithm as follows: Population size of 150 individuals, 2.5 million energy evaluations, and maximum of 27000 generations. AutoDock was run various times to obtain various docked conformations and used to calculate the predicted binding energy [23]. All graphics material was prepared using the Discovery studio (ver. 3.1, Accelrys Software Inc., CA, USA).

Docking method validation was done by redocking natural ligand receptor on the active site. The docking validation method was evaluated depend on the root-mean-square deviation (RMSD) and declared accurate if the value of RMSD smaller than $3.5 \AA$ [24]. In this study, the RMSD was 2.75 indicating this protocol and calculation parameter settings meet the criteria of validity docking methods.

\section{Statistical analysis}

IC50 was expressed as mean \pm standard deviation of separate groups for determinations in triplicates.

\section{RESULTS AND DISCUSSION}

The chemical composition of the M. alba essential oil

The essential oil of the flower of $M$. alba obtained steam distillation was pale yellow colorless oil and possessed an aromatic odor. It gives an average yield of $0.16 \%$ on a dry weight basis. In solvent extraction, hexane, diethyl ether, and dichloromethane were used as a solvent for getting concrete in $0.20 \%, 0.47 \%$, and $0.92 \%$, respectively. The yields of various extraction methods are shown in Fig. 1. 
The essential oils and scented extracts compositions of $M$. alba were determined by GC-MS. The volatile constituents were investigated by comparing the retention time and mass spectra of authentic samples with standard library NIST (2011). The analyses of steam distillation oil resulted in the identification of 36 compounds. The major components of the oil from the steam distillation were monoterpenoids $\beta$-linalool (65.03\%). Other four main characteristic components of this method were eugenol methyl ether (7.96\%), indole (3.66\%), linalool oxide $(2.02 \%)$, and pyran linalool oxide (1.92\%). Three solvents including hexane, diethyl ether, and dichloromethane were selected for extract scented components of $M$. alba flower. 29 constituents were detected in the total ion chromatogram profile of hexane extract. Of the 29 compounds identified, the group of five principal components including 2-methylbutanoic acid (36.54\%) together with $\beta$-linalool (16.30\%), palmitic acid (9.28\%), octacosane $(4.23 \%)$, and phenylethyl alcohol (4.19\%). $\beta$-linalool (37.32\%), 2-methylbutanoic acid (24.72\%), 4-hydroxybenzaldehydemethyl (9.10\%), (Z,Z)-9,12octadienoate $(3.03 \%)$, and eugenol methyl ether $(2.97 \%)$ was the five main compounds present in the diethyl ether extract. Odor profile of dichloromethane showed that the oil contains 29 constituents which represented $100 \%$ of its total composition. The five major components with include 2-methylbutanoic acid, $\beta$-linalool, 4-hydroxybenzaldehyde, ethyl 2-methylbutanoate, and 3-hydroxy-2-butanone were detected in $33.07 \%, 24.29 \%, 9.12 \%, 4.44 \%$, and $4.16 \%$ yields, respectively. Percent compositions of five major constituents of various extraction methods identified in the oil are given in Table 1. The GC-MS chromatograms of various extraction methods are shown in Fig. 2.

The results of our study were in accordance with those informed by Pensuk et al., $\beta$-linalool is the primary compound of $M$. alba flower

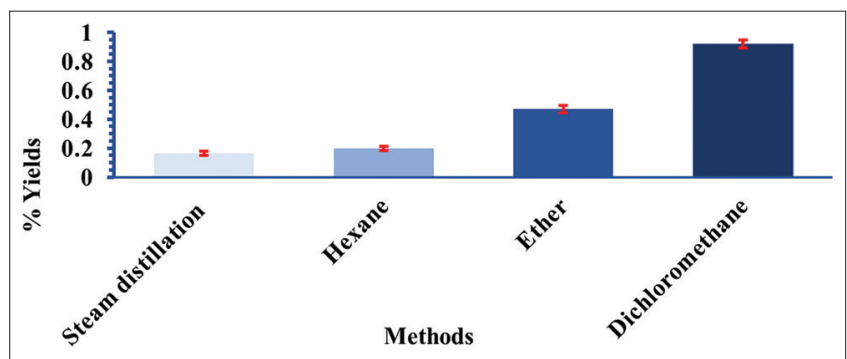

Fig. 1: Comparison of the yield of Michelia alba essential oils and scented extracts obtained from different methods, data are expressed as means \pm standard deviation $(n=3)$ essential oil extracted by steam distillation (66.92\% in content) [16] which was related to the finding of our current investigation which also obtained $\beta$-linalool to be the major component with the content being $65.03 \%$. In the case of hexane extraction, our result found that 2-methylbutanoic acid (36.54\%) and $\beta$-linalool (16.30\%) were a significant component. It was slight differences compared to the literature reported by Punjee et al. [17]. Punjee et al. found phenylethyl alcohol $(39.10 \%)$ and indole $(25.98 \%)$. In another investigation of Ueyama et al., GC-MS was used to analyze the volatile constituents of $M$. alba flowers cultivated in China and the major components were $\alpha$-terpineol, $\beta$-phenylethyl alcohol, $\beta$-pinene, and others [18]. The slight differences can probably be explained as the isolation and analysis conditions. The variation in the chemical composition of the essential oil from the plants studied is a direct relationship with the environment in which the plant grows the kind of soil [25].

\section{$\alpha$-Amylase activity}

In this study, the essential oil and scented extracts of M. alba were investigated as potential $\alpha$-amylase inhibitors. The $\alpha$-amylase inhibition assay results are summarized in Table 2 . The results were expressed as IC50 values (the concentration of the test samples required to inhibit $50 \%$ of the enzyme $\alpha$-amylase). The inhibitory effects of essential oil and scented extracts were compared with acarbose, clinically used as a specific inhibitor for $\alpha$-amylase. Different concentrations of essential oil and scented extracts were subjected to $\alpha$-amylase inhibitory assay. Steam distillation extract exhibited the highest inhibitory effect with an IC50 value of $0.67 \mathrm{mg} / \mathrm{ml}$, while hexane extract, diethyl ether extract, and dichloromethane extract of $M$. alba showed slightly lower $\alpha$-amylase inhibition activity with an IC50 value of $0.81,0.87$, and $0.80 \mathrm{mg} / \mathrm{ml}$, respectively. Comparatively to acarbose, reference compound showed IC50 values of $0.06 \mathrm{mg} / \mathrm{ml}$ which was 10 -fold higher than steam distillation extract. Based on this observation, steam distillation extract of $M$. alba showed considerably $\alpha$-amylase inhibitory effects, so the five major components including $\beta$-linalool, eugenol methyl ether, indole, linalool oxide, and pyran linalool oxide were selected for further in silico study. By molecular docking, the bound conformations and the binding affinity between five significant constituents of steam distillation extract of M. alba and $\alpha$-amylase as a target could be predicted.

\section{Docking studies}

Molecular modeling studies were accomplished to investigate the possible binding mode of five main components of steam distillation extract targeting the human pancreatic $\alpha$-amylase using AutoDock 4.2

Table 1: Major chemical compositions of M. alba essential oils from different extraction methods by GC-MS analysis

\begin{tabular}{|c|c|c|c|c|}
\hline Extraction method & Retention time, $\min$ & Area sum, $\%$ & Molecular formula & Possible compounds \\
\hline \multirow{5}{*}{ Steam distillation } & 29.303 & 65.03 & $\mathrm{C}_{10} \mathrm{H}_{18} \mathrm{O}$ & $\beta$-linalool \\
\hline & 39.802 & 7.96 & $\mathrm{C}_{11}^{10} \mathrm{H}_{14}^{18} \mathrm{O}_{2}$ & eugenol methyl ether \\
\hline & 48.053 & 3.66 & $\mathrm{C}_{8} \mathrm{H}_{7} \mathrm{~N}$ & Indole \\
\hline & 27.526 & 2.02 & $\mathrm{C}_{10}^{8} \mathrm{H}_{18}^{7} \mathrm{O}_{2}$ & linalool oxide \\
\hline & 34.498 & 1.92 & $\mathrm{C}_{10}^{10} \mathrm{H}_{18}^{18} \mathrm{O}_{2}^{2}$ & pyran linalool oxide \\
\hline \multicolumn{5}{|l|}{ Solvent extraction } \\
\hline \multirow[t]{4}{*}{ Steam distillation } & 32.291 & 36.54 & $\mathrm{C}_{5} \mathrm{H}$ & 2-methylbutanoic acid \\
\hline & 59.888 & 9.28 & $\mathrm{C}_{16}^{10} \mathrm{H}_{32}^{18} \mathrm{O}_{2}$ & palmitic acid \\
\hline & 59.081 & 4.23 & $\mathrm{C}_{28}^{16} \mathrm{H}_{58}^{32}$ & Octacosane \\
\hline & 37.888 & 4.19 & $\mathrm{C}_{8} \mathrm{H}_{10}^{58} \mathrm{O}$ & phenyl ethyl alcohol \\
\hline \multirow[t]{5}{*}{ Diethyl ether } & 29.249 & 37.32 & $\mathrm{C}_{10}^{8} \mathrm{H}_{18}^{10} \mathrm{O}$ & $\beta$-linalool \\
\hline & 32.297 & 24.72 & $\mathrm{C}_{5} \mathrm{H}_{10} \mathrm{O}_{2}$ & 2-methylbutanoic acid \\
\hline & 62.049 & 9.10 & $\mathrm{C}_{7}^{5} \mathrm{H}_{6} \mathrm{O}_{2}$ & 4-hydroxybenzaldehyde \\
\hline & 48.648 & 3.03 & $\mathrm{C}_{19} \mathrm{H}_{34} \mathrm{O}_{2}$ & Methyl (z, z)-9,12-octadienoate \\
\hline & 39.794 & 2.97 & $\mathrm{C}_{11}^{19} \mathrm{H}_{14}^{34} \mathrm{O}_{2}^{2}$ & eugenol methyl ether \\
\hline \multirow{4}{*}{ Dichloro methane } & 29.243 & 24.29 & $\mathrm{C}_{10}^{5} \mathrm{H}_{18}^{10} \mathrm{O}$ & $\beta$-linalool \\
\hline & 62.045 & 9.12 & $\mathrm{C}_{7} \mathrm{H}_{6} \mathrm{O}_{2}$ & 4-hydroxybenzaldehyde \\
\hline & 14.667 & 4.44 & $\mathrm{C}_{5} \mathrm{H}_{10} \mathrm{O}_{2}^{2}$ & ethyl 2-methylbutanoate \\
\hline & 22.258 & 4.16 & $\mathrm{C}_{5} \mathrm{H}_{10} \mathrm{O}_{2}$ & 3-hydroxy-2-butanone \\
\hline
\end{tabular}

M. alba: Michelia alba, GC-MS: Gas chromatography-mass spectrometry 
docking program. As shown in Table 3, selected compounds showed binding energy ranging between $-5.20 \mathrm{kcal} / \mathrm{mol}$ and $-2.88 \mathrm{kcal} / \mathrm{mol}$. Among five chemical constituents of $\mathrm{M}$. alba essential oil, $\beta$-linalool, showed that the best binding energy $(\Delta \mathrm{G})$ values is $-5.20 \mathrm{kcal} / \mathrm{mole}$. The docked pose of the $\alpha$-amylase enzyme with the ligands including $\beta$-linalool, pyran linalool oxide, eugenol methyl ether, indole, linalool

Table 2: $\alpha$-Amylase inhibition activity of essential oil and scented extracts of $M$. alba

\begin{tabular}{ll}
\hline Sample & IC50, $\mathbf{~ m g / m l}$ \\
\hline Steam distillation extract & $0.67 \pm 4.70$ \\
Hexane extract & $0.81 \pm 1.93$ \\
Diethyl ether extract & $0.87 \pm 3.40$ \\
Dichloromethane extract & $0.80 \pm 4.80$ \\
Acarbose* & $0.06 \pm 0.30$ \\
\hline
\end{tabular}

Values are mean \pm SD (n=3) SD: Standard deviation, *standard drug,

M. alba: Michelia alba oxide, and acarbose demonstrated the binding positions of the ligand with the target. The potential binding sites of the $\beta$-linalool was found to be TRP58, TRP59, TYR62, GLN63, LEU165, HIS299, ASP300, and HIS305 while eugenol methyl ether was bonded with TRP 58, TRP 59, TYR 62, ASP 157, LEU 162, HIS 299, and ASP 300. Further, analysis shows that pyran linalool oxide interacts with TRP58, TR62, ARG195, GLU233, HIS299, ASP300, and HIS305. The following vital residues TRP58, TRP59, TYR62, GLN63, LEU165, ASP197, HIS299, and ASP300 present in the binding site of the $\alpha$-amylase showed the interactions with linalool oxide. The eight interactions between indole and amino acid residues which included ARG343, VAL358, GLY359, PRO360, PR0361, ASN362, LYS368, and ASP381 were observed. In the case of acarbose, the best binding confirmation showed interactions with various vital residues including TYR2, SER3, PRO4, ARG252, GLU282, SER289, ASP290, PR0332, and PHE385. By the above study, the result further proved the $\alpha$-amylase inhibitory activity of all the five major components of steam distillation extract. The binding mode of selected compounds in the binding site pocket of $\alpha$-amylase is shown in Fig. 3.

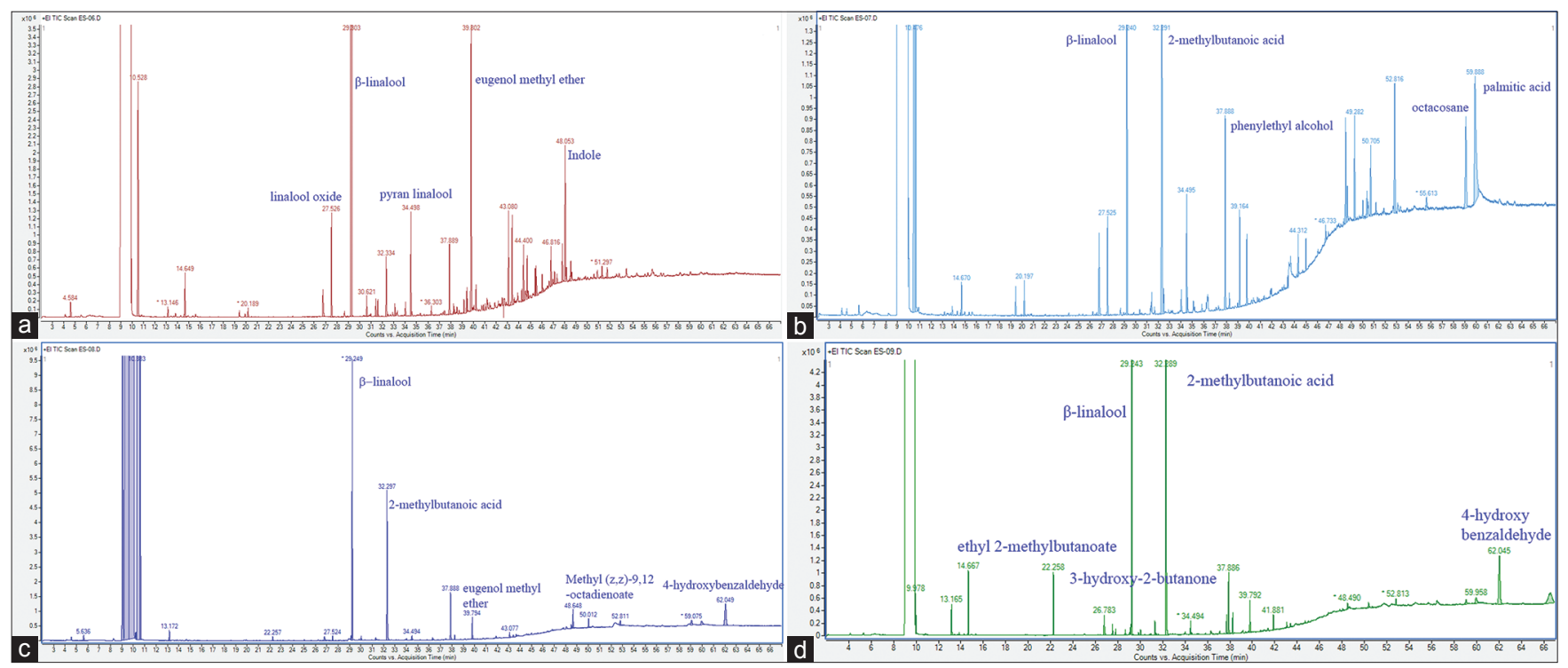

Fig. 2: Gas chromatography-mass spectrometry chromatograms of Michelia alba essential oils from different extraction methods. (a) Steam distillation, (b) hexane, (c) diethyl ether, and (d) dichloromethane

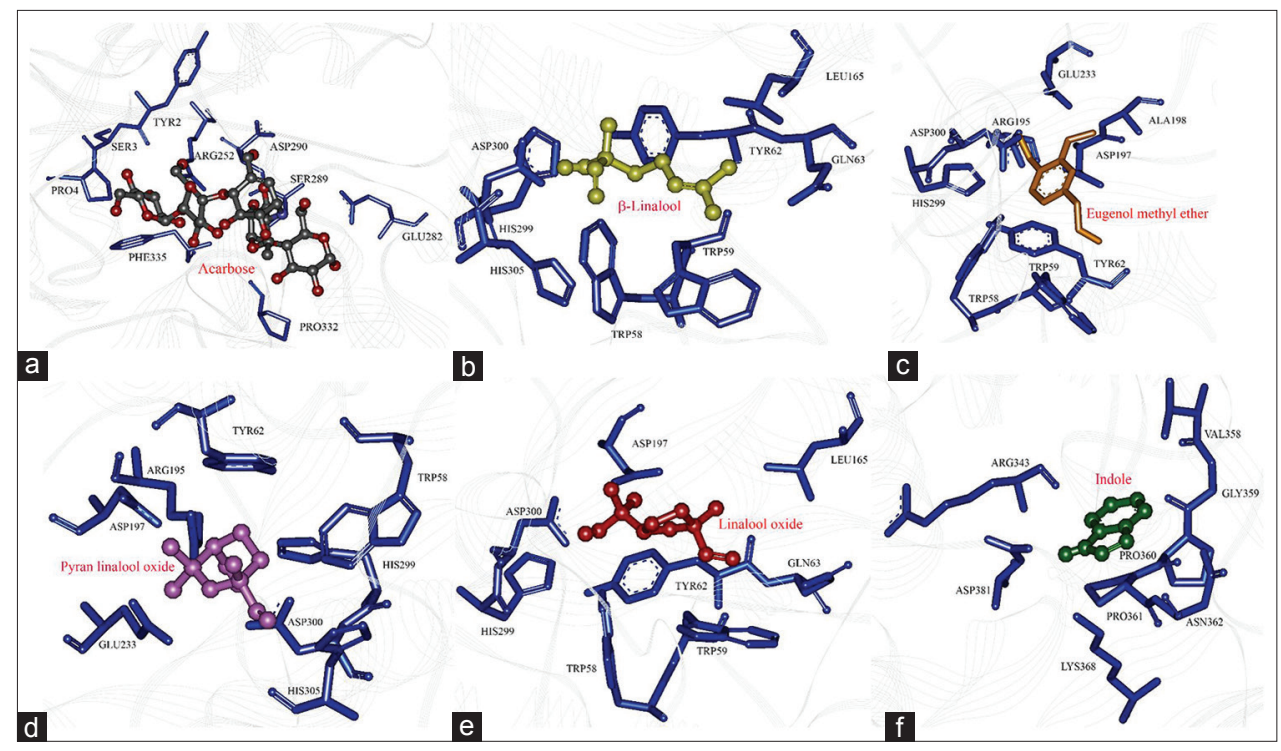

Fig. 3: The binding mode of selected compounds in the binding site pocket of $\alpha$-amylase. (a) Acarbose (b) $\beta$-linalool, (c) eugenol methyl ether, (d) pyran linalool oxide, (e) linalool oxide, and (f) indole 
Table 3: Binding of interactions of the major components of essential oil with $\alpha$-amylase (3BAJ)

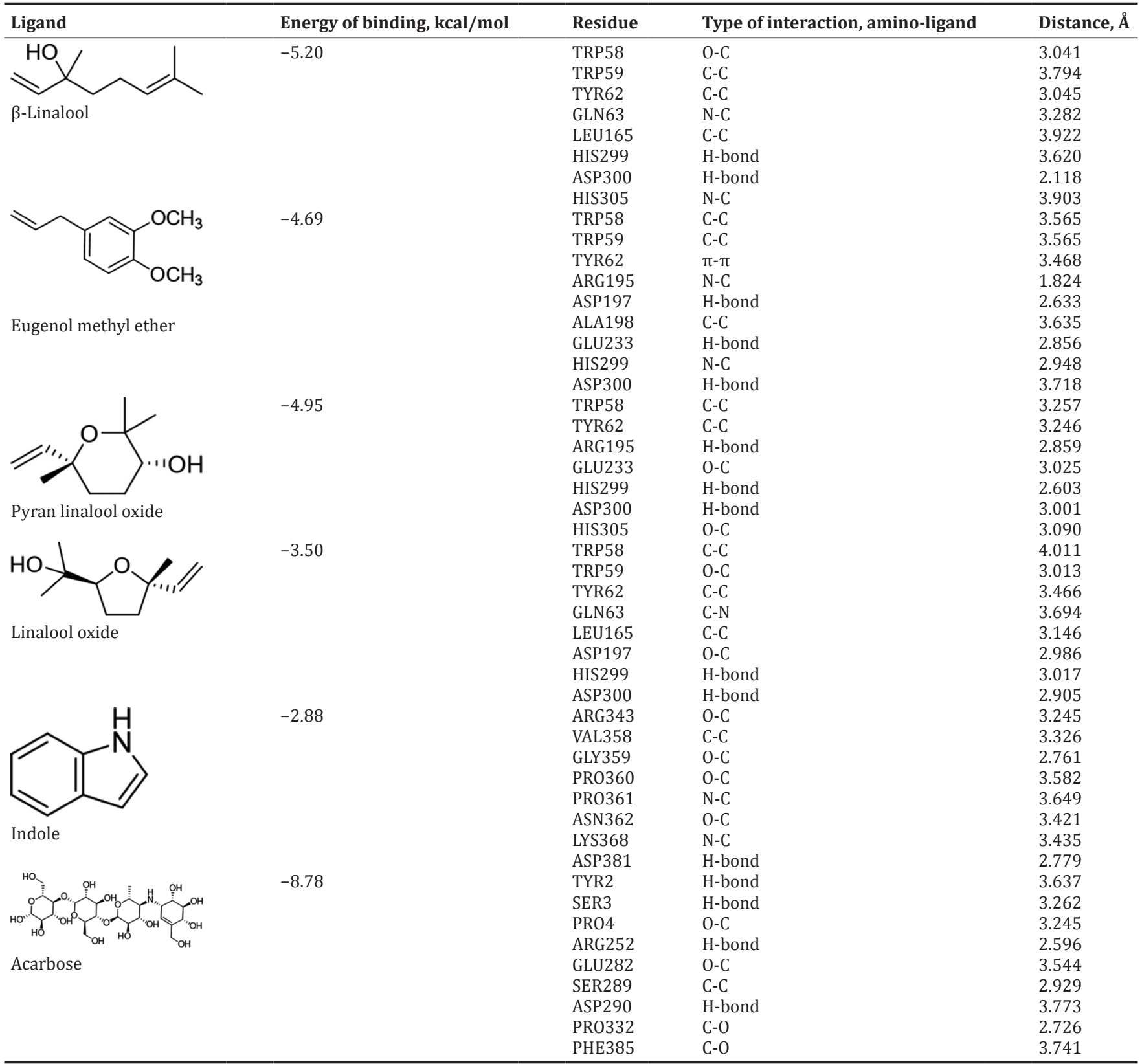

M. alba: Michelia alba

\section{CONCLUSION}

In this study, our finding revealed the chemical composition and the first report about the $\alpha$-amylase inhibitory activity of $M$. alba essential oil and scented extracts. In addition, the result of binding interactions of the ligand with $\alpha$-amylase has revealed that out of the major essential oil components of $M$. alba docked against 3BAJ. The highest docking interaction possessed by $\beta$-linalool. The results indicated that significant components of essential oil of $M$. alba could potentially play an essential role in the $\alpha$-amylase inhibitory activity. Our study open possibilities for the use of M. alba essential oils for controlling diabetic through its $\alpha$-amylase inhibitory activity. However, further, in vivo experiments and clinical trials are recommended.

\section{ACKNOWLEDGMENTS}

The authors are grateful to the Faculty of Science and Technology, Phranakhon Rajabhat University, for the Department of Chemistry,
Faculty of Science, Srinakharinwirot University, providing necessary research facilities.

\section{AUTHORS' CONTRIBUTIONS}

Thongchai Khammee designed and performed the experiments, analyzed the results, and wrote the research manuscript. Amornmart Jaratrungtawee helped in the design of experiments, analyzed statistical data, and coordinated in preparing the manuscript. Mayuso Kuno guided and provided required software for the study.

\section{CONFLICTS OF INTEREST}

The author(s) declare(s) that there are no conflicts of interest.

\section{REFERENCES}

1. WHO. Definition and Diagnosis of Diabetes Mellitus and Intermediate Hyperglycemia: Report of a WHO/IDF Consultation. Geneva: WHO 
Document Production Services;2006.

2. Sudha P, Zinjarde SS, Bhargava SY, Kumar AR. Potent alpha-amylase inhibitory activity of Indian ayurvedic medicinal plants. BMC Complement Altern Med 2011;11:5.

3. Sales PM, Souza PM, Simeoni LA, Magalhães PO, Silveira D. $\alpha$-amylase inhibitors: A review of raw material and isolated compounds from plant source. J Pharm Pharm Sci 2012;15:141-83.

4. Sonkamble VV, Wagh NS, Kamble LH. Inhibition of $\alpha$-amylase and $\alpha$-glucosidase by (6RS)-22-hydroxy-23,24,25,26,27-pentanorVitamin-D3-6,19-sulfurdioxide-adduct, manoalide and $5 \beta$-cholestane$3 \alpha, 7 \alpha, 12 \alpha, 24,25,26-$ hexol isolated from acetone extract of helianthus annuus 1. Seeds. Int J Pharm Pharm Sci 2018;10:39-49.

5. Anindita B, Bithin M, Sandip M, Kausik C, Tapan S. In vitro antidiabetic and anti-oxidant activities of ethanol extract of Tinospora sinensis. Int J Curr Pharm Res 2017;9:42-7.

6. Malviya N, Jain S, Malviya S. Antidiabetic potential of medicinal plants. Acta Pol Pharm 2010;67:113-8.

7. Patel DK, Prasad SK, Kumar R, Hemalatha S. An overview on antidiabetic medicinal plants having insulin mimetic property. Asian Pac J Trop Biomed 2012;2:320-30.

8. Balunas MJ, Kinghorn AD. Drug discovery from medicinal plants. Life Sci 2005;78:431-41.

9. Baimai V. Biodiversity in Thailand. J Roy Thai 2010;2:107-14.

10. Ali B, Al Wabel NA, Shams S, Ahamad A, Khan SA, Anwar F. Essential oils used in aromatherapy: A systemic review. Asian Pac J Trop Biomed 2015;5:601-11.

11. Yen HF, Hsieh CT, Hsieh TJ, Chang FR, Wang CK. In vitro antidiabetic effect and chemical component analysis of 29 essential oils products. J Food Drug Anal 2015;23:124-9.

12. Nishandhini S, Sudha V, Mallavarapu GR, Murugan R. Chemical compositions, $\alpha$-amylase inhibitory and antioxidant activities of the essential oils from unripe fruit pulp and leaves of Syzygium cumini. Int J Pharm Pharm Sci 2015;7:511-4.

13. Smitinand T. Thai Plant Names (Revised edition). Bangkok: Royal Forest Department; 2001.

14. Siriphat D. Jampee: Many Thai People Love this Flowers. Bangkok: Moh-chao-Ban; 2000.

15. Kumar D, Kumar S, Taprial S, Kashyap D, Kumar A, Prakash O.
A review of chemical and biological profile of genus Michelia. J Chin Integr Med 2012;10:1336-40.

16. Pensuk W, Padumanonda T, Pichaensoonthon C. Comparison of the chemical constituents in Michelia alba flower oil extracted by steam distillation, hexane extraction and enfleurage method. J Thai Trad Alter Med 2007;5:30-9.

17. PunjeeP,Dilokkunanant U, Sukkatta U, Vajrodaya S, Haruethaitanasan V, Pitpiangchan P. Scented extracts and essential oil extraction from Michelia alba DC. Kasetsart J (Nat Sci) 2009;43:197-203.

18. Ueyama Y, Hashimoto S, Nii H, Furukawa K. The chemical composition of the flower oil and the leaf oil of Michelia alba DC. J Essent Oil Res 1992;4:15-23.

19. Unnikrishnan PS, Suthindhiran K, Jayasri MA. Alpha-amylase inhibition and antioxidant activity of marine green algae and its possible role in diabetes management. Pharm Mag 2015;11:511-5.

20. Brayer GD, Luo Y, Withers SG. The structure of human pancreatic alpha-amylase at $1.8 \AA$ resolution and comparisons with related enzymes. Protein Sci 1995;4:1730-42.

21. Madeswaran A, Umamaheswari M, Asokkumar K, Sivashanmugam T, Subhadradevi V, Jagannath P. Computational drug discovery of potential phosphodiesterase inhibitors using in silico studies. Asian Pac J Trop Med 2012;2:S822-6.

22. Frisch MJ, Trucks GW, Schlegel HB, Scuseria GE, Robb MA, Cheeseman JR, et al. Gaussian 03, Revision c.02. Wallingford, CT: Gaussian; 2003.

23. Morris GM, Huey R, Lindstrom W, Sanner MF, Belew RK, Goodsell DS, et al. Auto dock 4 and auto dock tools 4: Automated docking with selective receptor flexibility. J Comput Chem 2009;30:2785-91.

24. Kontoyianni M, McClellan LM, Sokol GS. Evaluation of docking performance: Comparative data on docking algorithms. J Med Chem 2004;47:558-65.

25. Maria RM, Silvia A, Fátima C, Maria TT, Júlio CM. Antioxidant, antimicrobial and toxicological properties of Schinus molle L. essential oils. J Ethnopharmacol 2013;151:485-92. 